\title{
¿Por qué Revista de Cirugía?
}

\author{
Why Journal of Surgery?
}

\author{
Julio Yarmuch ${ }^{1}$
}

A lo largo de su existencia, más de 6 décadas, nuestra revista ha pasado por diferentes etapas.

En sus comienzos era un medio de divulgación de las actividades quirúrgicas o profesionales de los miembros de la Sociedad de Cirujanos.

Poco a poco, otros actores médicos, se fueron interesando en sus contenidos y también en publicar sus experiencias en ella. Mientras la revista se mantuvo solo en su edición en papel, rara vez recibió colaboraciones de artículos provenientes de más allá de las fronteras del país.

En octubre del año 2006, logramos su indexación en SCielo, proyecto de carácter regional, desarrollado en Chile por la Comisión Nacional de Investigación Científica y Tecnológica (CONICYT).

El proyecto SciELO es una iniciativa de FAPESP (Fundación de Apoyo a la Investigación del Estado de São Paulo) y de BIREME (Centro Latinoamericano y del Caribe de Información en Ciencias de la Salud). Desde 2002, el Proyecto cuenta con el apoyo del CNPq - Consejo Nacional de Desarrollo Científico y Tecnológico.

Nuestra incorporación a esta importante plataforma significó un salto en nuestra visibilidad nacional e internacional. Comenzaron a llegar para publicación artículos de toda América Latina, de España y en menor frecuencia, de otros países de Asia y Europa. Luego fuimos incluidos en varias otras plataformas, tales como Google Scholar, Scopus, Latindex, etc.

En el año 2009 fuimos aceptados en ThomsonReuters, ex ISI, lo que venía a traducir un claro reconocimiento de la posición alcanzada por la publicación. Lamentablemente, tres años después, debido a nuestros bajos índices de citación, fuimos sacados de la misma.

Con el objetivo de mejorar esta posición ingresamos a Elsevier, importante editorial privada europea, con una plataforma Web muy poderosa que facilitaba mucho el proceso editorial, pero que también implicaba un importante sacrificio económico para nuestra Sociedad de Cirujanos. Dos años después, en forma unilateral, esta empresa se desvinculó de las revistas chilenas y gran parte de las latinoamericanas por no convenir a sus intereses.

De esta manera nos vimos en la necesidad, desde fines del año 2017, de adoptar una nueva plataforma Web, la que es una creación de universidades norteamericano-canadienses, de menor costo operativo, pero de mayor complejidad en su proceso editorial.

En el año transcurrido hemos logrado ir venciendo las dificultades y la revista está saliendo adelante. En este momento contamos con una importante afluencia de artículos por publicar, los que provienen de las fuentes descritas.

En esta etapa, en calidad de coeditor, contamos con la inestimable colaboración de un joven cirujano, el Dr. Manuel Figueroa. Además, contamos con la excelente colaboración de un asesor cienciométrico, el Sr. Italo Costa, quien, además de habernos introducido en OJS y haber creado y mantenido nuestra página $\mathrm{Web}$, nos ha estado guiando en la labor de mejorar nuestros procesos y contenidos.

En Latinoamérica se ha dado el caso que muchas revistas nacieron de Sociedades Científicas como canal oficial de comunicación para sus socios, estas revistas fueron evolucionando y volviéndose más prestigiosas y abiertas al recibir contribuciones no sólo de los socios, sino de todos los miembros de la comunidad de investigadores de la disciplina.

Cuando se rompe esta barrera, se debe comenzar a revisar cuáles son los aspectos que pudieran influir de manera negativa en el crecimiento de la revista, tanto en la llegada a los investigadores como sus indicadores de citación e impacto; en el año 2017 se realizó una revisión de estos aspectos, y el que más destacó fue el nombre de la revista. En el caso "Revista Chilena de Cirugía", la palabra "chilena", al igual que en varias otras revistas que la llevan, genera un sesgo geográfico en los contenidos que se reciben, instalando la percepción de que es una revista cuyos contenidos publicados no son de interés y alcance internacional. Como se puede deducir,
${ }^{1}$ Editor.

Correspondencia a: jyarmuch9@gmail.com 
esto afecta directamente la calidad, visibilidad y citación de los artículos publicados.

Es por ello que, y luego de un amplio debate con el Directorio, con los editores y con nuestro asesor cienciométrico, se ha decidido que el nombre de la publicación cambie a Revista de Cirugía a contar del $\mathrm{N}^{\circ} 1$ de 2019. Por algún tiempo debe colocarse además, en pequeño, el nombre original de la re- vista, esto último para no perder la antigüedad de la misma. Ello implica el cambio de ISSN de las publicaciones en papel y en la Web.

Todo lo anterior con el fin de que, luego de algún tiempo, obtengamos nuestro ingreso a otras plataformas europeas y americanas que nos den el sello definitivo de revista internacionalmente conocida. 